\title{
Prognostic Significance of the Albumin-to-globulin Ratio for Advanced Urothelial Carcinoma Treated with Pembrolizumab: A Multicenter Retrospective Study
}

\author{
Satoru Taguchi \\ Kyorin University \\ Taketo Kawai ( $\sim$ taketokawai@yahoo.co.jp ) \\ University of Tokyo \\ Tohru Nakagawa \\ Teikyo University \\ Yu Nakamura \\ Kyorin University \\ Jun Kamei
}

Jichi Medical University

Daisuke Obinata

Nihon University

Kenya Yamaguchi

Nihon University

Tomoyuki Kaneko

Teikyo University

Shigenori Kakutani

Mitsui Memorial Hospital

Mayuko Tokunaga

Fraternity Memorial Hospital

Yukari Uemura

National Center For Global Health and Medicine

Yusuke Sato

University of Tokyo

Tetsuya Fujimura

Jichi Medical University

Hiroshi Fukuhara

Kyorin University

Yutaka Enomoto

Mitsui Memorial Hospital 


\section{Hiroaki Nishimatsu}

Fraternity Memorial Hospital

\section{Satoru Takahashi}

Nihon University

Haruki Kume

University of Tokyo

\section{Research Article}

Keywords: albumin-to-globulin ratio, bladder cancer, metastatic, neutrophil-to-lymphocyte ratio, pembrolizumab, REMARK, urothelial carcinoma

Posted Date: June 9th, 2021

DOl: https://doi.org/10.21203/rs.3.rs-569029/v1

License: (c) (i) This work is licensed under a Creative Commons Attribution 4.0 International License. Read Full License

Version of Record: A version of this preprint was published at Scientific Reports on August 2nd, 2021. See the published version at https://doi.org/10.1038/s41598-021-95061-z. 


\section{Abstract}

Although the albumin-to-globulin ratio (AGR) is a promising biomarker, no study has investigated its prognostic significance for advanced urothelial carcinoma (UC). This study conformed to the REporting recommendations for tumor MARKer prognostic studies (REMARK) criteria. We retrospectively reviewed 176 patients with advanced UC treated with pembrolizumab between 2018 and 2020. We evaluated the associations between pretreatment clinicopathological variables, including the AGR and performance status (PS), with progression-free survival, cancer-specific survival, and overall survival. The Cox proportional hazards model was used for univariate and multivariable analyses. The AGR was dichotomized as $<0.95$ and $\geq 0.95$ based on receiver operating characteristic curve analysis. After excluding 26 cases with missing data from the total of 176 cases, $109(73 \%)$ patients experienced disease progression, 75 (50\%) died from UC, and 6 (4\%) died of other causes (median survival = 12 months). Multivariate analyses identified PS $\geq 2$ and pretreatment $A G R<0.95$ as independent poor prognostic factors for all endpoints. Furthermore, a prognostic risk model incorporating these two variables achieved a relatively high concordance index for all endpoints. This is the first report to evaluate the significance of AGR in advanced UC. Pretreatment AGR $<0.95$ may serve as a prognostic marker for advanced UC treated with pembrolizumab.

\section{Introduction}

Urothelial carcinoma (UC), which mainly comprises bladder cancer and upper tract UC along with urethral cancer, is intractable, particularly when advanced (locally-advanced or metastatic) [1, 2]. Until recently, there was no established second-line regimen after failure of first-line platinum-based chemotherapy administered to patients with advanced UC: Patients' median survival time following first-line chemotherapy is approximately 14 months [1-4]. However, since the mid-2010s, immune checkpoint inhibitors have been used to treat advanced UC. Notably, the KEYNOTE-045 trial found that pembrolizumab, a humanized monoclonal antibody against programmed cell death protein 1 , achieves significantly better overall survival (OS) and objective response rates than cytotoxic chemotherapy (paclitaxel, docetaxel, or vinflunine) for patients with advanced UC with disease progression on or after platinum-containing chemotherapy [5]. Accordingly, pembrolizumab is currently used as an established second-line regimen [6].

Among biomarkers of patients with UC, the neutrophil-to-lymphocyte ratio (NLR) [7] is a well-established marker in patients with advanced UC [8-13], including those treated with pembrolizumab [9-13]. Similarly, the albumin-to-globulin ratio (AGR) is an established marker in oncology [14-24]. Although several studies assessed AGR in patients with UC [16-24], none evaluated its prognostic significance in the setting of "advanced UC." Therefore, the present study assessed the prognostic significance of the AGR together with the NLR and other pretreatment clinicopathological variables of patients with advanced UC who were treated with pembrolizumab.

\section{Methods}




\section{Ethical approval and informed consent.}

This study was approved by the Institutional Review Board (IRB) of the Graduate School of Medicine and Faculty of Medicine, The University of Tokyo (approval number: 10565), as well as that of each participating institution (IRB of Kyorin University School of Medicine; IRB of Teikyo University School of Medicine; IRB of Jichi Medical University; IRB of Nihon University School of Medicine; IRB of Mitsui Memorial Hospital; and IRB of The Fraternity Memorial Hospital). All methods were conducted in accordance with the 1964 Declaration of Helsinki and its later amendments or comparable ethical standards. Given the retrospective nature of the study, the requirement for informed consent was waived by the IRB of the Graduate School of Medicine and Faculty of Medicine, The University of Tokyo.

\section{Patients and study design.}

This retrospective study conformed to the REporting recommendations for tumor MARKer prognostic studies (REMARK) criteria [25] (Supplementary Table S1 online). We reviewed the records of 176 consecutive patients with advanced (locally-advanced or metastatic) UC treated with pembrolizumab at our seven affiliate institutions (five university hospitals and two tertiary referral hospitals) between January 2018 and July 2020. Blood tests were performed within 1 month after the initiation of pembrolizumab therapy. We excluded 26 patients whose data for AGR, NLR, or both were unavailable, leaving 150 patients for the final analysis (Fig. 1). A fixed dose of pembrolizumab (200 mg per patient) was intravenously administered every 3 weeks. All patients underwent evaluations every 1-6 months that included routine blood tests, chest X-ray, and computed tomography. The patients' charts were reviewed, and the status of each patient was assessed through office visits, telephone calls, or both.

\section{Pretreatment AGT, NLR, and other laboratory markers.}

Routine pretreatment blood tests, including serum total protein and albumin levels $(\mathrm{g} / \mathrm{dl})$, neutrophil and lymphocyte counts (cells $/ \mu \mathrm{L})$, hemoglobin $(\mathrm{g} / \mathrm{dL})$, creatinine $(\mathrm{mg} / \mathrm{dL})$, and C-reactive protein $(\mathrm{mg} / \mathrm{dL})$ were performed within 1 month before the start of pembrolizumab treatment. No patient had active infectious diseases during the blood tests. The AGR = [albumin/(total protein - albumin)]. The NLR was calculated by dividing the absolute neutrophil count by the absolute lymphocyte count. The eGFR $\left(\mathrm{mL} / \mathrm{min} / 1.73 \mathrm{~m}^{2}\right)$ was calculated from serum creatinine levels using the formula revised for Japanese patients [26].

\section{Endpoints and follow-up.}

We assessed the associations of pretreatment clinicopathological variables, including the AGR and NLR, with progression-free survival (PFS), cancer-specific survival (CSS), and OS. Disease progression was assessed according to the Response Evaluation Criteria in Solid Tumours (RECIST) version 1.1 [27]. 
Follow-up started on the day of initiating pembrolizumab treatment. Follow-up information was obtained as of October 2020.

\section{Statistical analysis.}

Receiver operating characteristic (ROC) curve analysis was used to determine the optimal cutoff values of the AGR and NLR. Sensitivity, specificity, and area under the curve (AUC) were calculated using a $2 \times 2$ contingency table incorporating each cutoff value. The optimal cutoff value of each ratio was determined by maximization of the Youden's index [Sensitivity - (1 - Specificity)]. The significance of the associations of the AGR with other variables were evaluated using the $\chi 2$ test or Spearman's rank correlation coefficient. Survival curves were generated using the Kaplan-Meier method and compared using log-rank tests. The Cox proportional hazard regression model was used for univariate and multivariate analyses for PFS, CSS, and OS.

A prognostic model for predicting PFS, CSS, and OS was constructed according to independent prognostic factors detected using multivariate analysis. Harrell's concordance index was calculated to quantify the model's prognostic discrimination [28]. All statistical analyses, except the concordance index, were performed using JMP Pro version 14.0.0 (SAS Institute, Cary, NC, USA). Harrell's concordance index was calculated by a biostatistician (Y.U.) using SAS version 9.4. $P<0.05$ indicates a significant difference.

\section{Results}

Patients' $(n=150)$ baseline characteristics are summarized in Table 1. The median follow-up and survival times were 7.5 (interquartile range [IQR], 4-14) months and 12 (IQR, 6-29) months, respectively. Overall, $48(32 \%)$ patients achieved an objective response, 109 (73\%) experienced disease progression, 75 (50\%) died of UC, and 6 (4\%) died of other causes. 
Table 1

Patients' characteristics at the start of pembrolizumab treatment $(n=150)$

\begin{tabular}{|c|c|}
\hline Parameter & Value \\
\hline Age, years, median (IQR) & $71(66-76)$ \\
\hline \multicolumn{2}{|l|}{ Sex, no. (\%): } \\
\hline Male & $111(74)$ \\
\hline Female & $39(26)$ \\
\hline \multicolumn{2}{|l|}{ ECOG PS, no. (\%): } \\
\hline 0 & $84(56)$ \\
\hline 1 & $48(32)$ \\
\hline 2 & $14(9)$ \\
\hline 3 & $4(3)$ \\
\hline \multicolumn{2}{|l|}{ Primary site, no. (\%): } \\
\hline Bladder & $66(44)$ \\
\hline Upper tract & $67(45)$ \\
\hline Both & $17(11)$ \\
\hline Resection of primary site, no. (\%) & $109(73)$ \\
\hline Lymph node metastasis, no. (\%) & $93(62)$ \\
\hline Visceral metastasis, no. (\%): & $106(71)$ \\
\hline Lung metastasis, no. (\%) & $59(39)$ \\
\hline Bone metastasis, no. (\%) & $30(20)$ \\
\hline Liver metastasis, no. (\%) & $27(18)$ \\
\hline \multicolumn{2}{|l|}{ No. of prior regimens, no. (\%): } \\
\hline 1 & $117(78)$ \\
\hline 2 & $25(17)$ \\
\hline 3 & $8(5)$ \\
\hline \multicolumn{2}{|c|}{ Pretreatment laboratory parameters, median (IQR): } \\
\hline AGR & $1.20(1.00-1.46)$ \\
\hline
\end{tabular}




\begin{tabular}{|ll|}
\hline Parameter & Value \\
\hline NLR & $3.34(2.20-5.36)$ \\
\hline Hemoglobin $(\mathrm{g} / \mathrm{dL})$ & $10.9(9.4-12.2)$ \\
\hline eGFR $\left(\mathrm{mL} / \mathrm{min} / 1.73 \mathrm{~m}^{2}\right)$ & $48.0(38.1-61.9)$ \\
\hline C-reactive protein $(\mathrm{mg} / \mathrm{dL})$ & $0.69(0.15-2.50)$ \\
\hline $\begin{array}{l}\text { Abbreviations: AGR = albumin-to-globulin ratio; ECOG PS = Eastern Cooperative Oncology Group } \\
\text { Performance Status; eGFR = estimated glomerular filtration rate; IQR = interquartile range; NLR }=\end{array}$ \\
\hline neutrophil-to-lymphocyte ratio
\end{tabular}

ROC curve analysis identified 0.95 as the optimal discriminatory cutoff value of the AGR through maximization of Youden's index [Sensitivity - (1 - Specificity)] for the endpoints of CSS and OS (Supplementary Fig. S1 online). Similarly, the most discriminatory cutoff value of NLR $=3$, given that the Youden's index was maximized at NLR $=3.02$ for CSS and OS (Supplementary Fig. S1 online).

The $\chi 2$ test revealed that the pathological Eastern Cooperative Oncology Group Performance Status (ECOG PS, $\geq 2, P<0.01$ ) and bone metastasis (yes, $P<0.01$ ) were significantly associated with AGR < 0.95. In contrast, the other variables (sex, primary site, resection of primary site, lymph node metastasis, lung metastasis, liver metastasis, and number of prior regimens) were not. Spearman's rank correlation coefficient showed a strongly significant negative correlation between C-reactive protein and the AGR ( $\rho=$ $-0.71, P<0.01)$, as well as a weakly significant negative correlation between the NLR and the AGR ( $\rho=$ $-0.41, P<0.01)$ and a weakly significant positive correlation between hemoglobin and the AGR $(\rho=+0.46$, $P<0.01)$.

Kaplan-Meier curves with log-rank tests showed significant associations of AGR $<0.95$ and NLR $\geq 3$ with shorter PFS, CSS, and OS (Fig. 2). Multivariate Cox proportional hazard regression analyses identified pretreatment $A G R<0.95$ as an independent indicator of poor prognosis for PFS together with the following: ECOG PS $\geq 2$ and liver metastasis (Table 2); CSS with ECOG PS $\geq 2$ (Table 3); and OS with ECOG PS $\geq 2$ (Table 4). Pretreatment NLR $\geq 3$ showed a non-significant trend for shorter CSS, whereas liver metastasis did for shorter OS (both $P=0.08$ ) (Tables 3 and 4). 
Table 2

Univariate and multivariate Cox proportional hazard regression analyses of PFS

\begin{tabular}{|c|c|c|c|c|c|}
\hline \multirow[t]{2}{*}{ Parameter } & \multirow[t]{2}{*}{ Cutoff } & \multicolumn{2}{|l|}{ Univariate } & \multicolumn{2}{|l|}{ Multivariate } \\
\hline & & $\mathrm{HR}(95 \% \mathrm{Cl})$ & $P$ & $\mathrm{HR}(95 \% \mathrm{Cl})$ & $P$ \\
\hline Age (years) & Continuous & $\begin{array}{l}1.01 \text { ( } 0.99 \text { to } 1.03) \text { per } \\
\text { score }\end{array}$ & 0.22 & & \\
\hline \multirow[t]{2}{*}{ Sex } & Male & Reference & 0.57 & & \\
\hline & Female & 0.88 (0.57 to 1.37$)$ & & & \\
\hline \multirow[t]{2}{*}{ ECOG PS } & $\leq 1$ & Reference & $<.01 *$ & Reference & $<.01 *$ \\
\hline & $\geq 2$ & 3.87 (2.27 to 6.62$)$ & & $\begin{array}{l}2.37 \text { ( } 1.30 \text { to } \\
4.34)\end{array}$ & \\
\hline \multirow[t]{2}{*}{ Primary site } & Bladder & Reference & 0.17 & & \\
\hline & $\begin{array}{l}\text { Upper tract or } \\
\text { both }\end{array}$ & 1.30 (0.89 to 1.91$)$ & & & \\
\hline \multirow{2}{*}{$\begin{array}{l}\text { Resection of primary } \\
\text { site }\end{array}$} & No & Reference & 0.44 & & \\
\hline & Yes & 0.85 (0.56 to 1.28$)$ & & & \\
\hline \multirow{2}{*}{$\begin{array}{l}\text { Lymph node } \\
\text { metastasis }\end{array}$} & No & Reference & 0.52 & & \\
\hline & Yes & 1.14 (0.77 to 1.67$)$ & & & \\
\hline \multirow[t]{2}{*}{ Lung metastasis } & No & Reference & 0.91 & & \\
\hline & Yes & 1.02 (0.70 to 1.50$)$ & & & \\
\hline \multirow[t]{2}{*}{ Bone metastasis } & No & Reference & 0.06 & & \\
\hline & Yes & 1.54 (0.98 to 2.44$)$ & & & \\
\hline \multirow[t]{2}{*}{ Liver metastasis } & No & Reference & $<.01 *$ & Reference & $\hat{0}_{0.05 *}$ \\
\hline & Yes & 2.51 (1.59 to 3.96$)$ & & $\begin{array}{l}1.83(1.12 \text { to } \\
2.99)\end{array}$ & \\
\hline
\end{tabular}

Abbreviations: $\mathrm{AGR}=$ albumin-to-globulin ratio; $\mathrm{Cl}$ = confidence interval; $\mathrm{ECOG}$ PS = Eastern Cooperative Oncology Group Performance Status; eGFR = estimated glomerular filtration rate; HR = hazard ratio; LLN = lower limit of normal; NLR = neutrophil-to-lymphocyte ratio; PFS = progression-free survival

TLLN of hemoglobin was set at $13.0 \mathrm{~g} / \mathrm{dL}$ for men and $11.5 \mathrm{~g} / \mathrm{dL}$ for women.

*Statistically significant 


\begin{tabular}{|c|c|c|c|c|c|}
\hline \multirow[t]{2}{*}{ Parameter } & \multirow[t]{2}{*}{ Cutoff } & \multicolumn{2}{|l|}{ Univariate } & \multicolumn{2}{|l|}{ Multivariate } \\
\hline & & $\mathrm{HR}(95 \% \mathrm{Cl})$ & $P$ & $\mathrm{HR}(95 \% \mathrm{Cl})$ & $P$ \\
\hline \multirow[t]{2}{*}{ No. of prior regimens } & 1 & Reference & 0.39 & & \\
\hline & $\geq 2$ & 1.21 (0.78 to 1.85$)$ & & & \\
\hline \multirow[t]{2}{*}{ AGR } & $\geq 0.95$ & Reference & $\hat{0.01 *}$ & Reference & $<.05^{\star}$ \\
\hline & $<0.95$ & 2.41 (1.57 to 3.68$)$ & & $\begin{array}{l}1.82 \text { (1.12 to } \\
2.97)\end{array}$ & \\
\hline \multirow[t]{2}{*}{ NLR } & $<3$ & Reference & $<.05^{\star}$ & Reference & 0.81 \\
\hline & $\geq 3$ & 1.49 (1.01 to 2.21$)$ & & $\begin{array}{l}1.05(0.68 \text { to } \\
1.63)\end{array}$ & \\
\hline \multirow[t]{2}{*}{ Hemoglobin (g/dL) } & $<\mathrm{LLN} \dagger$ & Reference & 0.42 & & \\
\hline & $\geq \mathrm{LLN}+$ & 0.81 (0.49 to 1.35$)$ & & & \\
\hline \multirow{2}{*}{$\begin{array}{l}\text { eGFR }(\mathrm{mL} / \mathrm{min} / 1.73 \\
\left.\mathrm{m}^{2}\right)\end{array}$} & $<60$ & Reference & 0.29 & & \\
\hline & $\geq 60$ & 0.80 (0.53 to 1.21$)$ & & & \\
\hline \multirow[t]{2}{*}{$\begin{array}{l}\text { C-reactive protein } \\
(\mathrm{mg} / \mathrm{dL})\end{array}$} & $<0.5$ & Reference & $<.01 *$ & Reference & 0.45 \\
\hline & $\geq 0.5$ & 1.75 (1.19 to 2.59$)$ & & $\begin{array}{l}1.20(0.75 \text { to } \\
1.90)\end{array}$ & \\
\hline \multicolumn{6}{|c|}{$\begin{array}{l}\text { Abbreviations: } A G R=\text { albumin-to-globulin ratio; } \mathrm{Cl}=\text { confidence interval; ECOG PS = Eastern } \\
\text { Cooperative Oncology Group Performance Status; } \text { eGFR = estimated glomerular filtration rate; HR = } \\
\text { hazard ratio; } L L N=\text { lower limit of normal; NLR = neutrophil-to-lymphocyte ratio; PFS = progression-free } \\
\text { survival }\end{array}$} \\
\hline \multicolumn{6}{|c|}{ tLLN of hemoglobin was set at $13.0 \mathrm{~g} / \mathrm{dL}$ for men and $11.5 \mathrm{~g} / \mathrm{dL}$ for women. } \\
\hline \multicolumn{6}{|c|}{ *Statistically significant } \\
\hline
\end{tabular}


Table 3

Univariate and multivariate Cox proportional hazard regression analyses of CSS

\begin{tabular}{|c|c|c|c|c|c|}
\hline \multirow[t]{2}{*}{ Parameter } & \multirow[t]{2}{*}{ Cutoff } & \multicolumn{2}{|l|}{ Univariate } & \multicolumn{2}{|l|}{ Multivariate } \\
\hline & & $\mathrm{HR}(95 \% \mathrm{Cl})$ & $P$ & $\mathrm{HR}(95 \% \mathrm{Cl})$ & $P$ \\
\hline Age (years) & Continuous & $\begin{array}{l}1.02(1.00 \text { to } 1.05) \\
\text { per score }\end{array}$ & 0.05 & & \\
\hline \multirow[t]{2}{*}{ Sex } & Male & Reference & 0.79 & & \\
\hline & Female & 1.07 (0.64 to 1.81$)$ & & & \\
\hline \multirow[t]{2}{*}{ ECOG PS } & $\leq 1$ & Reference & $<.01 *$ & Reference & $<_{0.01 *}$ \\
\hline & $\geq 2$ & 6.45 (3.68 to 11.33$)$ & & $\begin{array}{l}3.52 \text { (1.76 to } \\
7.05)\end{array}$ & \\
\hline \multirow[t]{2}{*}{ Primary site } & Bladder & Reference & $<.05^{\star}$ & Reference & 0.17 \\
\hline & $\begin{array}{l}\text { Upper tract or } \\
\text { both }\end{array}$ & 1.62 (1.01 to 2.59$)$ & & $\begin{array}{l}1.40 \text { (0.86 to } \\
2.28)\end{array}$ & \\
\hline \multirow{2}{*}{$\begin{array}{l}\text { Resection of primary } \\
\text { site }\end{array}$} & No & Reference & 0.51 & & \\
\hline & Yes & $0.84(0.50$ to 1.41$)$ & & & \\
\hline \multirow[t]{2}{*}{$\begin{array}{l}\text { Lymph node } \\
\text { metastasis }\end{array}$} & No & Reference & $<.05^{\star}$ & Reference & 0.24 \\
\hline & Yes & 1.75 (1.06 to 2.88$)$ & & $\begin{array}{l}1.38 \text { (0.81 to } \\
2.35 \text { ) }\end{array}$ & \\
\hline \multirow[t]{2}{*}{ Lung metastasis } & No & Reference & 0.70 & & \\
\hline & Yes & 1.10 (0.69 to 1.75$)$ & & & \\
\hline \multirow[t]{2}{*}{ Bone metastasis } & No & Reference & $<.05^{\star}$ & Reference & 0.32 \\
\hline & Yes & 1.92 (1.11 to 3.34$)$ & & $\begin{array}{l}1.35(0.74 \text { to } \\
2.46)\end{array}$ & \\
\hline Liver metastasis & No & Reference & <. $0.01 *$ & Reference & 0.18 \\
\hline \multicolumn{6}{|c|}{$\begin{array}{l}\text { Abbreviations: AGR = albumin-to-globulin ratio; } \mathrm{Cl} \text { = confidence interval; } \mathrm{CSS} \text { = cancer-specific survival; } \\
\text { ECOG PS = Eastern Cooperative Oncology Group Performance Status; eGFR = estimated glomerular } \\
\text { filtration rate; HR = hazard ratio; LLN = lower limit of normal; NLR = neutrophil-to-lymphocyte ratio }\end{array}$} \\
\hline
\end{tabular}




\begin{tabular}{|c|c|c|c|c|c|}
\hline \multirow[t]{2}{*}{ Parameter } & \multirow[t]{2}{*}{ Cutoff } & \multicolumn{2}{|l|}{ Univariate } & \multicolumn{2}{|l|}{ Multivariate } \\
\hline & & $\mathrm{HR}(95 \% \mathrm{Cl})$ & $P$ & $\mathrm{HR}(95 \% \mathrm{Cl})$ & $P$ \\
\hline & Yes & 2.52 (1.49 to 4.26$)$ & & $\begin{array}{l}1.51(0.82 \text { to } \\
2.78)\end{array}$ & \\
\hline \multirow[t]{2}{*}{ No. of prior regimens } & 1 & Reference & 0.30 & & \\
\hline & $\geq 2$ & 1.31 (0.79 to 2.16$)$ & & & \\
\hline \multirow[t]{2}{*}{ AGR } & $\geq 0.95$ & Reference & $<0.01 *$ & Reference & $\dot{0.05 *}$ \\
\hline & $<0.95$ & 3.19 (1.96 to 5.21$)$ & & $\begin{array}{l}2.19 \text { (1.19 to } \\
4.04)\end{array}$ & \\
\hline \multirow[t]{2}{*}{ NLR } & $<3$ & Reference & $\dot{0.01 *}$ & Reference & 0.08 \\
\hline & $\geq 3$ & 2.48 (1.44 to 4.26$)$ & & $\begin{array}{l}1.70(0.94 \text { to } \\
3.07)\end{array}$ & \\
\hline \multirow[t]{2}{*}{ Hemoglobin (g/dL) } & $<$ LLN† & Reference & & & \\
\hline & $\geq \mathrm{LLN} \dagger$ & 0.58 (0.30 to 1.13$)$ & 0.11 & & \\
\hline \multirow{2}{*}{$\begin{array}{l}\text { eGFR }(\mathrm{mL} / \mathrm{min} / 1.73 \\
\left.\mathrm{m}^{2}\right)\end{array}$} & $<60$ & Reference & 0.35 & & \\
\hline & $\geq 60$ & 0.78 (0.46 to 1.32$)$ & & & \\
\hline \multirow[t]{2}{*}{$\begin{array}{l}\text { C-reactive protein } \\
(\mathrm{mg} / \mathrm{dL})\end{array}$} & $<0.5$ & Reference & $<.01 *$ & Reference & 0.48 \\
\hline & $\geq 0.5$ & 2.31 (1.41 to 3.76$)$ & & $\begin{array}{l}1.24 \text { (0.69 to } \\
2.23)\end{array}$ & \\
\hline \multicolumn{6}{|c|}{$\begin{array}{l}\text { Abbreviations: AGR = albumin-to-globulin ratio; } \mathrm{Cl}=\text { confidence interval; } \mathrm{CSS}=\text { cancer-specific survival; } \\
\text { ECOG PS = Eastern Cooperative Oncology Group Performance Status; } \text { EGFR = estimated glomerular } \\
\text { filtration rate; HR = hazard ratio; LLN = lower limit of normal; NLR = neutrophil-to-lymphocyte ratio }\end{array}$} \\
\hline \multicolumn{6}{|c|}{ tLLN of hemoglobin was set at $13.0 \mathrm{~g} / \mathrm{dL}$ for men and $11.5 \mathrm{~g} / \mathrm{dL}$ for women. } \\
\hline \multicolumn{6}{|c|}{ *Statistically significant } \\
\hline
\end{tabular}


Table 4

Univariate and multivariate Cox proportional hazard regression analyses of OS

\begin{tabular}{|c|c|c|c|c|c|}
\hline \multirow[t]{2}{*}{ Parameter } & \multirow[t]{2}{*}{ Cutoff } & \multicolumn{2}{|l|}{ Univariate } & \multicolumn{2}{|l|}{ Multivariate } \\
\hline & & $\mathrm{HR}(95 \% \mathrm{Cl})$ & $P$ & $\mathrm{HR}(95 \% \mathrm{Cl})$ & $P$ \\
\hline Age (years) & Continuous & $\begin{array}{l}1.02(1.00 \text { to } 1.05) \text { per } \\
\text { score }\end{array}$ & 0.05 & & \\
\hline \multirow[t]{2}{*}{ Sex } & Male & Reference & 0.90 & & \\
\hline & Female & 0.97 (0.58 to 1.62$)$ & & & \\
\hline \multirow[t]{2}{*}{ ECOG PS } & $\leq 1$ & Reference & $\dot{0.01 *}$ & Reference & $\dot{0.01 *}$ \\
\hline & $\geq 2$ & 5.64 (3.23 to 9.83$)$ & & $\begin{array}{l}3.53(1.85 \text { to } \\
6.74)\end{array}$ & \\
\hline \multirow[t]{2}{*}{ Primary site } & Bladder & Reference & $<.05^{*}$ & Reference & 0.12 \\
\hline & $\begin{array}{l}\text { Upper tract or } \\
\text { both }\end{array}$ & 1.63 (1.04 to 2.57$)$ & & $\begin{array}{l}1.44(0.90 \text { to } \\
2.28)\end{array}$ & \\
\hline \multirow{2}{*}{$\begin{array}{l}\text { Resection of primary } \\
\text { site }\end{array}$} & No & Reference & 0.60 & & \\
\hline & Yes & 0.87 (0.53 to 1.44$)$ & & & \\
\hline \multirow{2}{*}{$\begin{array}{l}\text { Lymph node } \\
\text { metastasis }\end{array}$} & No & Reference & 0.12 & & \\
\hline & Yes & 1.44 (0.91 to 2.29$)$ & & & \\
\hline \multirow[t]{2}{*}{ Lung metastasis } & No & Reference & 0.58 & & \\
\hline & Yes & 1.14 (0.73 to 1.77$)$ & & & \\
\hline \multirow[t]{2}{*}{ Bone metastasis } & No & Reference & 0.05 & & \\
\hline & Yes & 1.71 (0.99 to 2.95$)$ & & & \\
\hline Liver metastasis & No & Reference & $<_{0.01 *}$ & Reference & 0.08 \\
\hline
\end{tabular}

Abbreviations: $\mathrm{AGR}=$ albumin-to-globulin ratio; $\mathrm{Cl}$ = confidence interval; $\mathrm{ECOG} \mathrm{PS}=$ Eastern Cooperative Oncology Group Performance Status; eGFR = estimated glomerular filtration rate; HR = hazard ratio; LLN = lower limit of normal; NLR = neutrophil-to-lymphocyte ratio; OS = overall survival

tLLN of hemoglobin was set at $13.0 \mathrm{~g} / \mathrm{dL}$ for men and $11.5 \mathrm{~g} / \mathrm{dL}$ for women.

*Statistically significant 


\begin{tabular}{|c|c|c|c|c|c|}
\hline \multirow[t]{2}{*}{ Parameter } & \multirow[t]{2}{*}{ Cutoff } & \multicolumn{2}{|l|}{ Univariate } & \multicolumn{2}{|l|}{ Multivariate } \\
\hline & & $\mathrm{HR}(95 \% \mathrm{Cl})$ & $P$ & HR (95\% Cl) & $P$ \\
\hline & Yes & 2.59 (1.57 to 4.27$)$ & & $\begin{array}{l}1.65(0.94 \text { to } \\
2.90)\end{array}$ & \\
\hline \multirow[t]{2}{*}{ No. of prior regimens } & 1 & Reference & 0.52 & & \\
\hline & $\geq 2$ & $1.18(0.72$ to 1.94$)$ & & & \\
\hline \multirow[t]{2}{*}{ AGR } & $\geq 0.95$ & Reference & $<.01 *$ & Reference & $<.01 *$ \\
\hline & $<0.95$ & 3.18 (1.98 to 5.09$)$ & & $\begin{array}{l}2.60 \text { ( } 1.48 \text { to } \\
4.59)\end{array}$ & \\
\hline \multirow[t]{2}{*}{ NLR } & $<3$ & Reference & $<.01 *$ & Reference & 0.37 \\
\hline & $\geq 3$ & 1.95 (1.19 to 3.18$)$ & & $\begin{array}{l}1.28 \text { (0.75 to } \\
2.19 \text { ) }\end{array}$ & \\
\hline \multirow[t]{2}{*}{ Hemoglobin $(\mathrm{g} / \mathrm{dL})$} & $<\mathrm{LLN}+$ & Reference & 0.07 & & \\
\hline & $\geq \mathrm{LLN} \dagger$ & $0.54(0.28$ to 1.04$)$ & & & \\
\hline \multirow{2}{*}{$\begin{array}{l}\text { eGFR }(\mathrm{mL} / \mathrm{min} / 1.73 \\
\left.\mathrm{m}^{2}\right)\end{array}$} & $<60$ & Reference & 0.72 & & \\
\hline & $\geq 60$ & $0.92(0.56$ to 1.49$)$ & & & \\
\hline \multirow[t]{2}{*}{$\begin{array}{l}\text { C-reactive protein } \\
(\mathrm{mg} / \mathrm{dL})\end{array}$} & $<0.5$ & Reference & $<.01^{*}$ & Reference & 0.57 \\
\hline & $\geq 0.5$ & 2.04 (1.28 to 3.23$)$ & & $\begin{array}{l}1.17(0.67 \text { to } \\
2.05)\end{array}$ & \\
\hline \multicolumn{6}{|c|}{$\begin{array}{l}\text { Abbreviations: AGR = albumin-to-globulin ratio; } \mathrm{Cl}=\text { confidence interval; ECOG PS = Eastern } \\
\text { Cooperative Oncology Group Performance Status; eGFR = estimated glomerular filtration rate; HR = } \\
\text { hazard ratio; LLN = lower limit of normal; NLR = neutrophil-to-lymphocyte ratio; OS = overall survival }\end{array}$} \\
\hline \multicolumn{6}{|c|}{ tLLN of hemoglobin was set at $13.0 \mathrm{~g} / \mathrm{dL}$ for men and $11.5 \mathrm{~g} / \mathrm{dL}$ for women. } \\
\hline \multicolumn{6}{|c|}{ *Statistically significant } \\
\hline
\end{tabular}

A prognostic risk model designed to predict PFS, CSS, and OS was developed according to the two shared risk factors in the multivariate analyses for all endpoints as follows: no risk, AGR $\geq 0.95$ and $P S \leq 1$; one risk, $A G R<0.95$ or $P S \geq 2$; and two risks, $A G R<0.95$ and $P S \geq 2$. A significant difference was found among the survival profiles of the three risk groups (Fig. 3). The Harrell's concordance indices of this model were PFS, 0.63; CSS, 0.68; and OS, 0.67. 


\section{Discussion}

To our knowledge, this study is the first study to assess the prognostic significance of the AGR in patients with advanced UC. Here we analyzed a multi-institutional cohort of 150 patients with advanced UC patients treated with pembrolizumab. We found that pretreatment AGR $<0.95$ and ECOG PS $\geq 2$ were independent predictors of PFS, CSS, and OS. Furthermore, we developed a prognostic risk model incorporating these two variables, which classified patients into three risk groups with significantly different PFS, CSS, and OS values. The model achieved a relatively high Harrell's concordance index for all study endpoints.

Although the concept of AGR was introduced long ago, it was not applied to oncology until the 2010s [14, 15]. Several studies assessed the prognostic significance of the AGR of patients with UC [16-24] in settings of bladder cancer treated with radical cystectomy [16, 17], non-muscle-invasive bladder cancer [18], and upper tract UC treated with radical nephroureterectomy [19-24]. Most of these studies [16-23] demonstrate the utility of the AGR as a readily available predictive biomarker for patients with UC. To our knowledge, the present study is the first to demonstrate the potential utility of the AGR in the setting of advanced UC, and thus adds further evidence in this field.

The link between a low AGR and poor outcomes of patients with cancer is not fully established but may be explained in general terms as follows [23,29]: First, previous studies show that poor nutritional status or hypoalbuminemia is a predictor of poor prognosis for patients with cancer [29]. Second, chronic inflammation involving serum globulins is required for tumor proliferation, immune evasion, and metastasis. Evidence indicates that serum globulins secreted by tumor-related cells promote tumor development, immunosuppression, and metastasis [29]. Third, a low AGR may thus more sensitively reflect the degree of poor nutritional status (hypoalbuminemia) and tumor progression (hyperglobulinemia) than either measure alone, and may therefore serve as a highly significant prognostic biomarker [23].

Similar to the concept of the AGR (i.e. use of a ratio), the NLR was developed in 2001 by Roman Zahorec [7] and has subsequently been investigated in oncology. Numerous studies show an association with an increased NLR with worse outcomes of certain malignancies including UC [8-13]. The NLR sensitively reflects the degree of tumor progression; this is because both an increased neutrophil-dependent inflammatory reaction and a decreased lymphocyte-mediated anti-tumor immune response contribute to the elevation of the NLR $[8,30]$.

We previously reported the prognostic significance of the NLR using a multi-institutional cohort of 185 patients with advanced UC undergoing first-line chemotherapy [8]. Pretreatment NLR $\geq 3$ was identified as an independent predictor of CSS and OS together with ECOG PS $\geq 2$ and liver metastasis, whereas the AGR was not evaluated [8]. In the present study, pretreatment NLR $\geq 3$ was significantly associated with all endpoints of PFS, CSS, and OS on univariate analyses (Table 2-4), and showed a non-significant trend for shorter CSS on a multivariate analysis $(P=0.08)$ (Table 3$)$. These data indicate that the NLR may still serve as a valid biomarker in the setting of later-line pembrolizumab. 
We further reported the critical impact of liver metastasis on worse outcomes in the said study [8]. In the present study, liver metastasis was significantly associated with all endpoints of PFS, CSS, and OS on univariate analyses (Table 2-4), and was identified as an independent predictor of shorter PFS (Table 2) with showing a non-significant trend for shorter OS $(P=0.08)$ (Table 4$)$ on multivariate analyses. Although liver metastasis was not incorporated into the final risk model applied here, it undoubtedly serves as an essential prognostic marker for advanced UC, even in the era of immune checkpoint inhibitors.

The limitations of this study include its retrospective design and the limited number of patients. Further studies with larger populations are required to validate our results.

In conclusion, pretreatment AGR $<0.95$ may serve as a prognostic marker for patients with advanced UC treated with pembrolizumab. Our newly developed prognostic risk model, including pretreatment AGR and ECOG PS, may serve as an excellent discriminator of survival.

\section{Abbreviations}

AGR = albumin-to-globulin ratio; $\mathrm{AUC}=$ area under the curve; $\mathrm{Cl}$ = confidence interval; $\mathrm{CSS}$ = cancerspecific survival; ECOG PS = Eastern Cooperative Oncology Group Performance Status; eGFR = estimated glomerular filtration rate; $\mathrm{HR}$ = hazard ratio; IQR = interquartile range; IRB = Institutional Review Board; LLN = lower limit of normal; NLR = neutrophil-to-lymphocyte ratio; OS = overall survival; PFS = progression-free survival; RECIST = Response Evaluation Criteria in Solid Tumours; REMARK = REporting recommendations for tumor MARKer prognostic studies; ROC = receiver operating characteristic

\section{Declarations}

\section{Acknowledgment}

We thank Edanz Group (https://en-author-services.edanzgroup.com/ac) for editing a draft of this manuscript.

\section{Funding}

We did not receive funding/grant support for this study.

\section{Conflict of interest}

The authors declare that they have no conflict of interest.

\section{Data availability}


The datasets generated during and/or analyzed during the current study are available from the corresponding author upon reasonable request.

\section{References}

1. Taguchi S, Nakagawa T, Hattori M et al (2013) Prognostic factors for metastatic urothelial carcinoma undergoing cisplatin-based salvage chemotherapy. Jpn J Clin Oncol 43:923-928.

2. Taguchi $S$, Nakagawa T, Uemura $Y$ et al (2016) Validation of major prognostic models for metastatic urothelial carcinoma using a multi-institutional cohort of the real world. World J Urol 34:163-171.

3. von der Maase H, Hansen SW, Roberts JT et al (2000) Gemcitabine and cisplatin versus methotrexate, vinblastine, doxorubicin, and cisplatin in advanced or metastatic bladder cancer: results of a large, randomized, multinational, multicenter, phase III study. J Clin Oncol 18:3068-3077.

4. von der Maase H, Sengelov L, Roberts JT et al (2005) Long-term survival results of a randomized trial comparing gemcitabine plus cisplatin, with methotrexate, vinblastine, doxorubicin, plus cisplatin in patients with bladder cancer. J Clin Oncol 23:4602-4608.

5. Bellmunt J, de Wit R, Vaughn DJ et al; KEYNOTE-045 Investigators (2017) Pembrolizumab as Second-Line Therapy for Advanced Urothelial Carcinoma. N Engl J Med 376:1015-1026.

6. National Comprehensive Cancer Network (2020) NCCN Clinical Practice Guidelines in Oncology: Bladder Cancer (Version 2.2020). https://www.nccn.org/professionals/physician_gls/pdf/bladder.pdf. Accessed 8 Nov 2020.

7. Zahorec R (2001) Ratio of neutrophil to lymphocyte counts-rapid and simple parameter of systemic inflammation and stress in critically ill. Bratisl Lek Listy 102:5-14.

8. Taguchi S, Nakagawa T, Matsumoto A et al (2015) Pretreatment neutrophil-to-lymphocyte ratio as an independent predictor of survival in patients with metastatic urothelial carcinoma: A multiinstitutional study. Int J Urol 22: 638-643.

9. Ogihara K, Kikuchi E, Shigeta K et al (2020) The pretreatment neutrophil-to-lymphocyte ratio is a novel biomarker for predicting clinical responses to pembrolizumab in platinum-resistant metastatic urothelial carcinoma patients. Urol Oncol 38:602.e1-602.e10.

10. Shimizu T, Miyake M, Hori S et al (2020) Clinical Impact of Sarcopenia and Inflammatory/Nutritional Markers in Patients with Unresectable Metastatic Urothelial Carcinoma Treated with Pembrolizumab. Diagnostics (Basel) 10:310.

11. Etani T, Naiki T, Sugiyama Y et al (2020) Low Geriatric Nutritional Risk Index as a Poor Prognostic Marker for Second-Line Pembrolizumab Treatment in Patients with Metastatic Urothelial Carcinoma: A Retrospective Multicenter Analysis. Oncology 98:876-883

12. Tamura D, Jinnouchi N, Abe M et al (2020) Prognostic outcomes and safety in patients treated with pembrolizumab for advanced urothelial carcinoma: experience in real-world clinical practice. Int $J$ Clin Oncol 25:899-905. 
13. Yamamoto Y, Yatsuda J, Shimokawa M et al (2021) Prognostic value of pre-treatment risk stratification and post-treatment neutrophil/lymphocyte ratio change for pembrolizumab in patients with advanced urothelial carcinoma. Int J Clin Oncol 26:169-177

14. Azab BN, Bhatt VR, Vonfrolio $S$ et al (2013) Value of the pretreatment albumin to globulin ratio in predicting long-term mortality in breast cancer patients. Am J Surg 206:764-770.

15. Azab B, Kedia S, Shah N et al (2013) The value of the pretreatment albumin/globulin ratio in predicting the long-term survival in colorectal cancer. Int $\mathrm{J}$ Colorectal Dis 28:1629-1636.

16. Liu J, Dai Y, Zhou F et al (2016) The prognostic role of preoperative serum albumin/globulin ratio in patients with bladder urothelial carcinoma undergoing radical cystectomy. Urol Oncol 34:484.e1484.e8.

17. Liu Z, Huang H, Li S et al (2017) The prognostic value of preoperative serum albumin-globulin ratio for high-grade bladder urothelial carcinoma treated with radical cystectomy: A propensity scorematched analysis. J Cancer Res Ther 13:837-843.

18. Niwa N, Matsumoto K, Ide H et al (2018) Prognostic Value of Pretreatment Albumin-to-Globulin Ratio in Patients With Non-Muscle-Invasive Bladder Cancer. Clin Genitourin Cancer 16:e655-e661.

19. Zhang B, Yu W, Zhou LQ et al (2015) Prognostic Significance of Preoperative Albumin-Globulin Ratio in Patients with Upper Tract Urothelial Carcinoma. PLoS One 10:e0144961.

20. Xu H, Tan P, Ai J et al (2018) Prognostic Impact of Preoperative Albumin-Globulin Ratio on Oncologic Outcomes in Upper Tract Urothelial Carcinoma Treated With Radical Nephroureterectomy. Clin Genitourin Cancer 16:e1059-e1068.

21. Otsuka M, Kamasako T, Uemura T et al (2018) Prognostic role of the preoperative serum albumin : globulin ratio after radical nephroureterectomy for upper tract urothelial carcinoma. Int J Urol 25:871-878.

22. Fukushima H, Kobayashi M, Kawano K et al (2018) Prognostic Value of Albumin/Globulin Ratio in Patients with Upper Tract Urothelial Carcinoma Patients Treated with Radical Nephroureterectomy. Anticancer Res 38:2329-2334.

23. Omura S, Taguchi S, Miyagawa S et al (2020) Prognostic significance of the albumin-to-globulin ratio for upper tract urothelial carcinoma. BMC Urol 20:133.

24. Pradere B, D'Andrea D, Schuettfort VM et al; UTUC collaboration (2020) Pre-therapy serum albuminto-globulin ratio in patients treated with neoadjuvant chemotherapy and radical nephroureterectomy for upper tract urothelial carcinoma. World J Urol. doi: 10.1007/s00345-020-03479-3. [Online ahead of print]

25. McShane LM, Altman DG, Sauerbrei W et al; Statistics Subcommittee of the NCI-EORTC Working Group on Cancer Diagnostics (2005) Reporting recommendations for tumor marker prognostic studies (REMARK). J Natl Cancer Inst 97:1180-1184.

26. Matsuo S, Imai E, Horio M et al, Collaborators developing the Japanese equation for estimated GFR (2009) Revised equations for estimated GFR from serum creatinine in Japan. Am J Kidney Dis 53:982-992. 
27. Eisenhauer EA, Therasse P, Bogaerts $\mathrm{J}$ et al (2009) New response evaluation criteria in solid tumours: revised RECIST guideline (version 1.1). Eur J Cancer 45:228-247.

28. Harrell FE Jr, Lee KL, Mark DB (1996) Multivariable prognostic models: issues in developing models, evaluating assumptions and adequacy, and measuring and reducing errors. Stat Med 15:361-387.

29. He J, Pan H, Liang W et al (2017) Prognostic effect of albumin-to-globulin ratio in patients with solid tumors: a systematic review and meta-analysis. J Cancer 8:4002-4010.

30. Templeton AJ, McNamara MG, Šeruga B et al (2014) Prognostic role of neutrophil-to-lymphocyte ratio in solid tumors: a systematic review and meta-analysis. J Natl Cancer Inst 106:dju124.

\section{Figures}

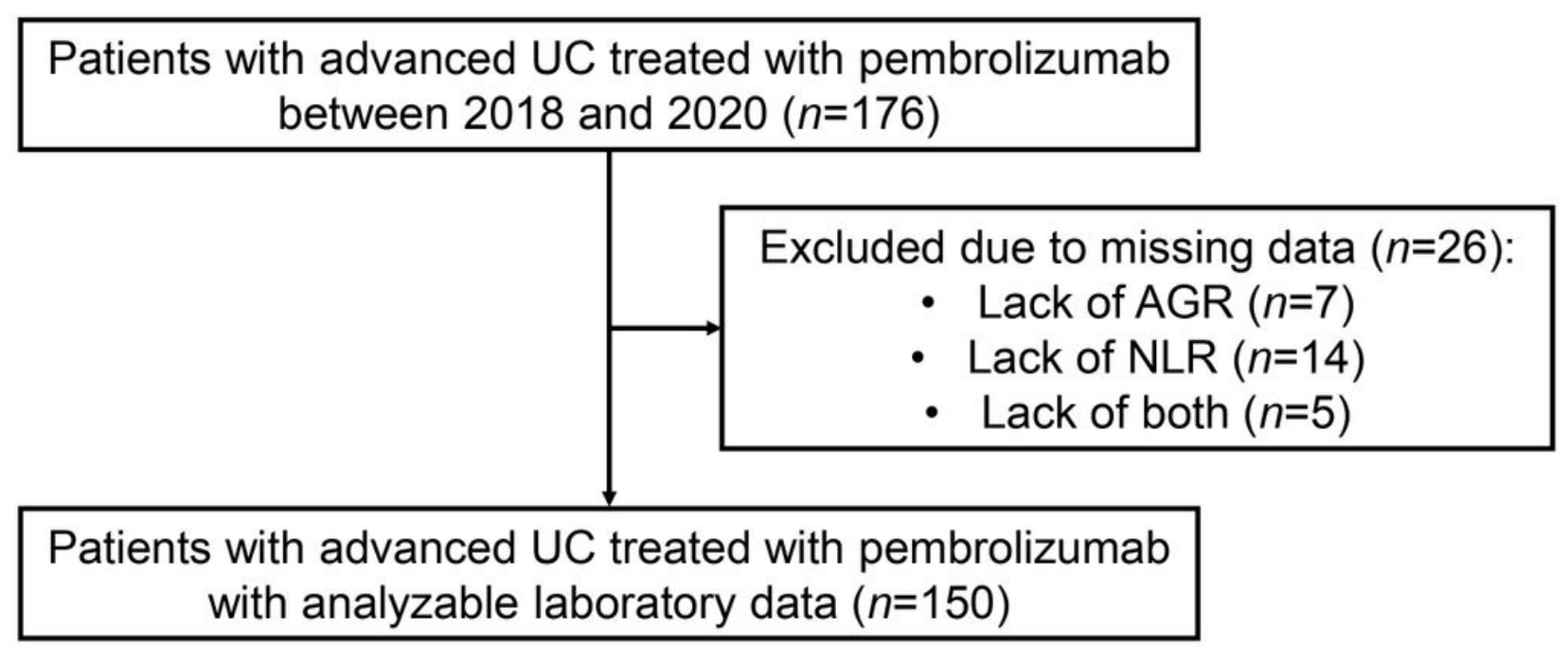

Figure 1

Patient selection. Abbreviations: AGR = albumin-to-globulin ratio; NLR = neutrophil-to-lymphocyte ratio 

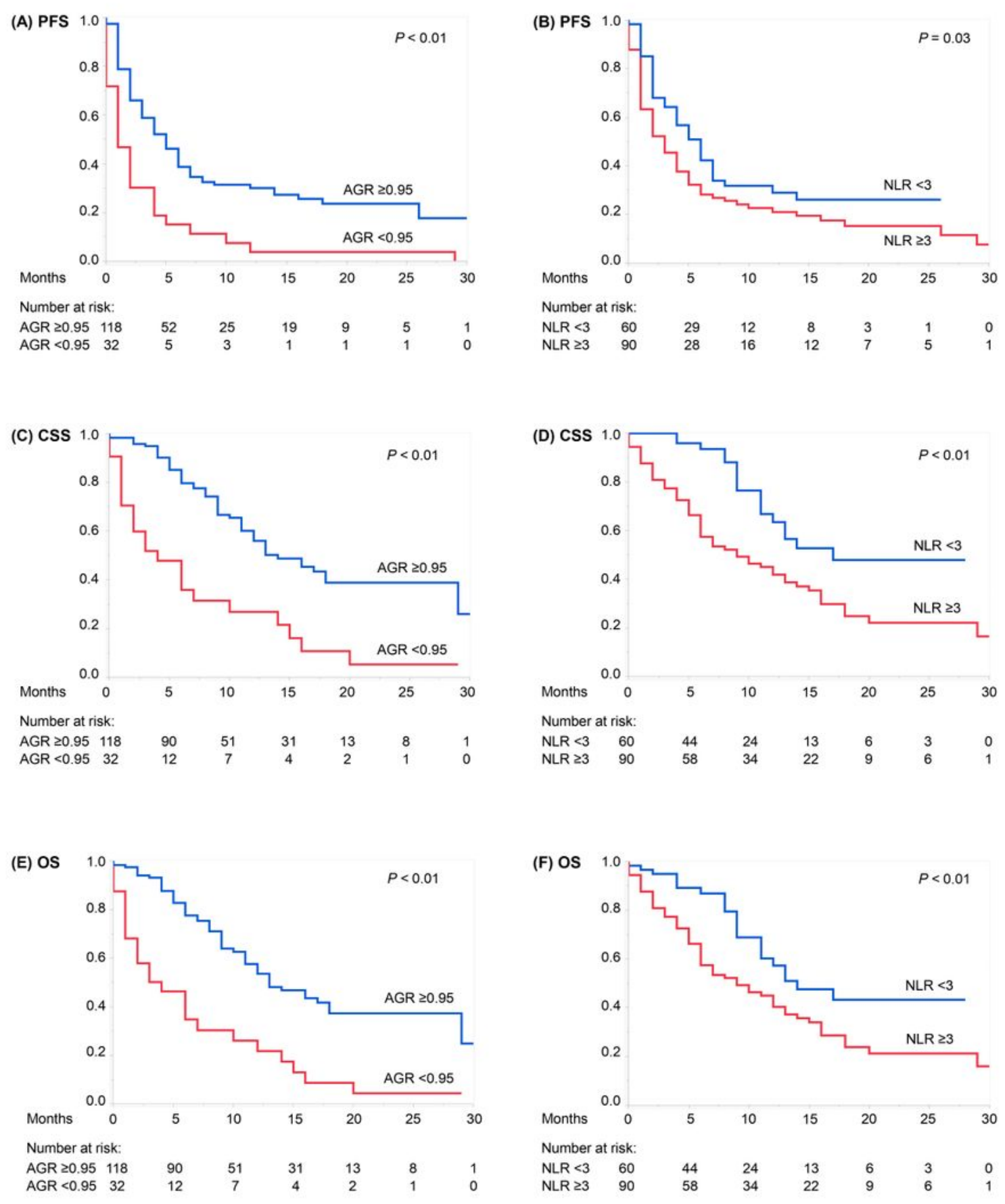

\section{Figure 2}

Kaplan-Meier curves depicting (A) PFS of patients with AGR $\geq 0.95$ vs $<0.95$, (B) PFS of patients with NLR $<3$ vs NLR $\geq 3$, (C) CSS of patients with $A G R \geq 0.95$ vs $<0.95$, (D) CSS in patients with NLR $<3$ versus $N L R \geq 3$, (E) OS of patients with AGR $\geq 0.95$ vs $<0.95$, and (F) OS of patients with NLR $<3$ vs NLR $\geq 3$. Abbreviations: AGR = albumin-to-globulin ratio; CSS = cancer-specific survival; NLR = neutrophil-tolymphocyte ratio; OS = overall survival; PFS = progression-free survival 

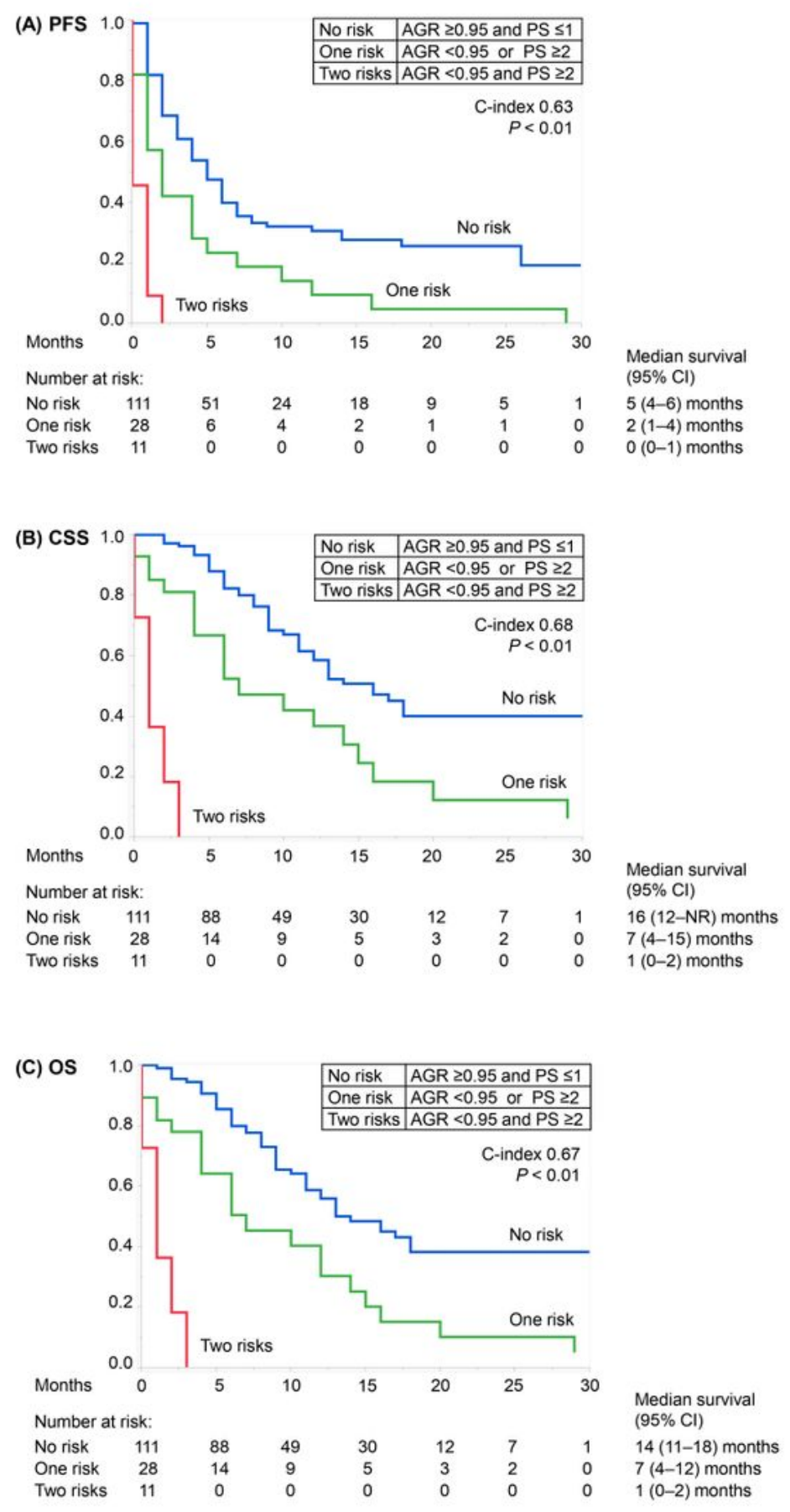

\section{Figure 3}

Kaplan-Meier curves depicting (A) PFS, (B) CSS, and (C) OS according to the prognostic risk model (no risk, $A G R \geq 0.95$ and $P S \leq 1$; one risk, $A G R<0.95$ or $P S \geq 2$; and two risks, $A G R<0.95$ and $P S \geq 2$ ).

\section{Supplementary Files}


This is a list of supplementary files associated with this preprint. Click to download.

- SupplementaryFig.S1.tif

- SupplementaryTableS1.docx 